Acta Cryst. (2002). A58 (Supplement), C219

PREDICTING STRUCTURES AND ENERGETICS IN TRANSITION METAL POLYHYDRIDE COMPLEXES

M. B. Hall C. E. Webster

Texas A\&M University Chemistry Ross and Spence Streets P. O. Box 30012

COLLEGE STATION TEXAS 77842-3012 USA

Density functional calculations make excellent predictions for the geometry and energy of stable structures for the tetrahydrides of cyclopentadienyl osimum phosphines and arsines and for the tetrahydrides of tris(pyrazolyl)borato iridium. The latter seven-coordinate species are predicted to have an edge-bridged octahedral structure ( $C s$ symmetry) rather than the expected face-bridged structure ( $C 3 v$ symmetry). The calculations predict several other low energy structures that can be invoked to explain this species spectroscopy.

\section{Keywords: POLYHYDRIDES QUANTUM CHEMISTRY DENSITY} FUNCTIONAL THEORY

Acta Cryst. (2002). A58 (Supplement), C219

\title{
INTERCONVERSION OF DIHYDROGEN AND HYDRIDE LIGANDS IN TRANSITION METAL COMPLEXES
}

J. Eckert

Los Alamos National Laboratory LANSCE, Mail Stop H805 LOS ALAMOS NM 87545 USA

A particularly important aspect of the chemistry of dihydrogen ligands in transition metal complexes are the direct interactions between dihydrogen and hydride ligands, which can result in rapid exchange or interconversion among these species. The dynamics of this process can be faster than what can be probed by NMR, and may well contribute to the very large thermal ellipsoid observed in diffraction experiments on such compounds. We have carried out detailed inelastic neutron scattering (INS) studies over a wide range of temperatures on systems, where extremely rapid dihydrogen-hydride exchange is deduced from NMR. These include the series $\operatorname{IrXH}_{2}\left(\mathrm{H}_{2}\right)\left(\mathrm{P}^{\mathrm{i}} \mathrm{Pr}_{3}\right)$ here $\mathrm{X}$ is a halide, the Fe complex $\mathrm{FeH}_{2}\left(\mathrm{H}_{2}\right)\left(\mathrm{PEtPh}_{2}\right)$, as well as the Rh complex $\mathrm{Tp}^{*} \mathrm{RhH}_{2}$ $\left(\mathrm{H}_{2}\right)$. The results show that the presence of dihydrogen-hydride exchange is evident in the high temperature quasielastic neutron scattering spectrum from these ligands. Both average jump distances for the motion of the hydrogens in this process and the associated activation energies have been derived from the neutron scattering data and can be related to structural and energetic results obtained from diffraction and theoretical studies.

The work described in this talk is part of several close collaborations, primarily with the groups of M. B. Hall and C. M. Jensen, and with E. Clot, A. Albinati and others.

This work has benefited from the use of facilities at the Manuel Lujan Jr. Neutron Scattering Center, a National User Facility funded as such by the Office of Basic Energy Sciences, U S Department of Energy.

Keywords: DIHYDROGEN, TRANSITION METAL COMPLEXES, DYNAMICS

\author{
Acta Cryst. (2002). A58 (Supplement), C219 \\ 2D-3D TRANSITIONS IN LUNG SURFACTANT \\ K.Y.C. Lee \\ The University of Chicago Chemistry 5735 S. Ellis Avenue CHICAGO IL \\ 60637 USA
}

$\underline{\text { K. Yvon }}$

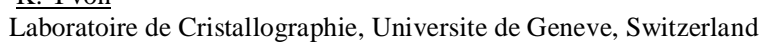

Metal hydrides containing transition metal hydrogen complexes provide new opportunities for efficient and safe hydrogen storage. Their hydrogen-to-metal ratios reach values of up to $\mathrm{H} / \mathrm{M}=4.5\left(\mathrm{BaReH}_{9}\right)$ and thus surpass the hydrogen-to-carbon ratios of hydrocarbons (methane : $\mathrm{H} / \mathrm{C}=4$ ); their hydrogen volume efficiencies exceed that of liquid hydrogen by a factor of up to two $\left(\mathrm{Mg}_{2} \mathrm{FeH}_{6}\right)$, their weight efficiencies exceed $5 \%\left(\mathrm{Mg}_{3} \mathrm{MnH}_{7}\right)$, and their hydrogen dissociation temperatures under 1 bar hydrogen pressure range from about $100^{\circ} \mathrm{C}\left(\mathrm{NaKReH}_{9}\right)$ to $400^{\circ} \mathrm{C}\left(\mathrm{CaMgNiH}_{4}\right)$. Their crystal chemistry is extremely rich and shows a large inventory of transition metal hydrido complexes that often conform to the 18-electron rule. The aim of current work is to find lighter and cheaper metal hydrides that decompose at or near ambient conditions, to develop new predictive concepts, to find new synthetic routes, and to understand the factors that govern metal hydride formation, hydrogen contents and thermal stability. In this talk some aspects of that work will be highlighted. Given the absence of suitable single crystals, most structure work has to be performed on polycrystalline samples. The importance of advanced radiation sources (synchrotrons and high-flux neutron sources), modern diffraction equipment and advances in powder diffraction methodology will be underlined.

\section{Keywords: HYDRIDES HYDRIDO COMPLEXES TRANSITION METAL}

\section{Acta Cryst. (2002). A58 (Supplement), C219
NEW METAL HYDRIDES CONTAINING TRANSITION METAL HYDROGEN COMPLEXES}

